\title{
An Analysis of Self-assessment Model of College Students -- Based on the Innovation Perspective of Independent Academy Student Evaluation System
}

\author{
Yuan Zhou ${ }^{1, \text { a }}$ \\ ${ }^{1}$ Wuhan Technology and Business University, Wuhan, Hubei, China \\ a274527013@qq.com
}

\begin{abstract}
Keywords: Student evaluation system, Self-assessment, Evaluation indicators, Independent Academy.

Abstract. The reform of student evaluation system in the mode of cultivating applied talents in independent academy is to establish a comprehensive student evaluation system which is mainly open, flexible and individualized. Self-assessment, not only from the evaluation of the main diversity of innovation, but also from the way, the methods and the content were improved to help reduce the lack of evaluation and invalid evaluation. Self-assessment model can be from the starting point of students learning motivation. First, it must be formulate self-goal, through the goal of guiding action, and then to form stage results, contrast evaluation indicators to draw conclusions. Finally, through the evaluation conclusion in the evaluation process to form the improvement direction of feedback learning initiative, and become the next guidance basis for the establishment of learning goals.
\end{abstract}

\section{Introduction}

In 2014, The Sate Council printed and distributed the decision on accelerating the development of the modern occupational education, fully implementing the strategy of accelerating the development of the modern occupational education. It makes clear that we should encourage independent academy fix a position on application technology type institution of higher learning when they want to turns into independent institution of higher learning. Independent academies should change the talent mode of elite education in the training of application-oriented talents mode, from the emphasis on academic and theoretical personnel training into professional and practical talent mode emphasizing practical ability. This also requires independent academies of student evaluation system reform to change the existing evaluation model, which is to pass the examination for learning purposes, to memorize the book knowledge as the main way of learning. The new model will be establish a more open, flexible and personalized comprehensive evaluation system based on application ability assessment.

The traditional assessment method is entirely by the teachers involved in the whole process of student evaluation, which is the way of dynamic observation and static test results combined with the subjective evaluation. Of course, one of the reform way of traditional evaluation is to establish an effective evaluation mechanism and multi-dimensional assessment methods. It means the subjects of the evaluation can be teachers or business mentors, and also can be the self of student, because students are the main body of the best dynamic learning process evaluation. Self-assessment refers to the students according to the evaluation criteria to plan the study, to drive and judge their own learning, self-monitoring and self-adjustment in the learning process, in order to promote the development of learning. In theoretical perspective, self-assessment is based on the metacognition as the foundation; it followed the essence of reflective learning, which is thinking about thinking itself-ability of reflection, understanding and control of personal learning (Schraw and Dennison, 1994).

\section{The Construction of Self-assessment Model}

The purpose of college students evaluation is not simply Distinguish between students academic achievement, its ultimate goal should be to improve learning and improve ability. By constructing the 
self assessment system, on the one hand, teachers can participate in the self assessment system, and together to make learning plans with students, often with students to discuss and develop the learning evaluation standard, and help students improve their ability eventually. On the other hand, students can also dynamically record and feedback their learning results, through the evaluation criteria to grasp the method of self-assessment. And from understanding the evaluation of their strengths and weaknesses, get improved learning information, so as to promote and improve the self-learning. On the other hand, students can also dynamically record and feedback their learning results, through the evaluation criteria to grasp the method of self-assessment. And from understanding the evaluation of theirself strengths and weaknesses, they will get Improved learning information, so as to promote and improve the self-learning.

Self-assessment model can be from the starting point of students learning motivation. First, it must be formulate self-goal, through the goal of guiding action, and then to form stage results, contrast evaluation indicators to draw conclusions. Finally, through the evaluation conclusion in the evaluation process to form the improvement direction of feedback learning initiative, and become the next guidance basis for the establishment of learning goals. The following diagram is a self-assessment model diagram 1-1.

Self -assessment model is constructed according to the learning process. From absorption knowledge to conversion knowledge and to form ability, these three aspects give the evaluation index and standard, so the key of the model is to determine the index evaluation standard of each level. Independent academy in the setting of assessment methods is necessary to pay attention to the application of the theory of assessment of knowledge, also want to pay attention to the assessment of the practical skills, but also reflect on the occupation literacy requirements. In addition, the non-professional ability of students should also be included in the self-assessment system, which is the blind spot of traditional teaching evaluation, reflects the significance of self evaluation on teaching assessment. In the design of the self-assessment system of the specific student evaluation system, the evaluation criteria should be set up according to different the types of majors.

Under the application talents training mode of independent colleges, the innovation of student evaluation is the improvement and innovation of the existing evaluation system according to the characteristics of applied talents.

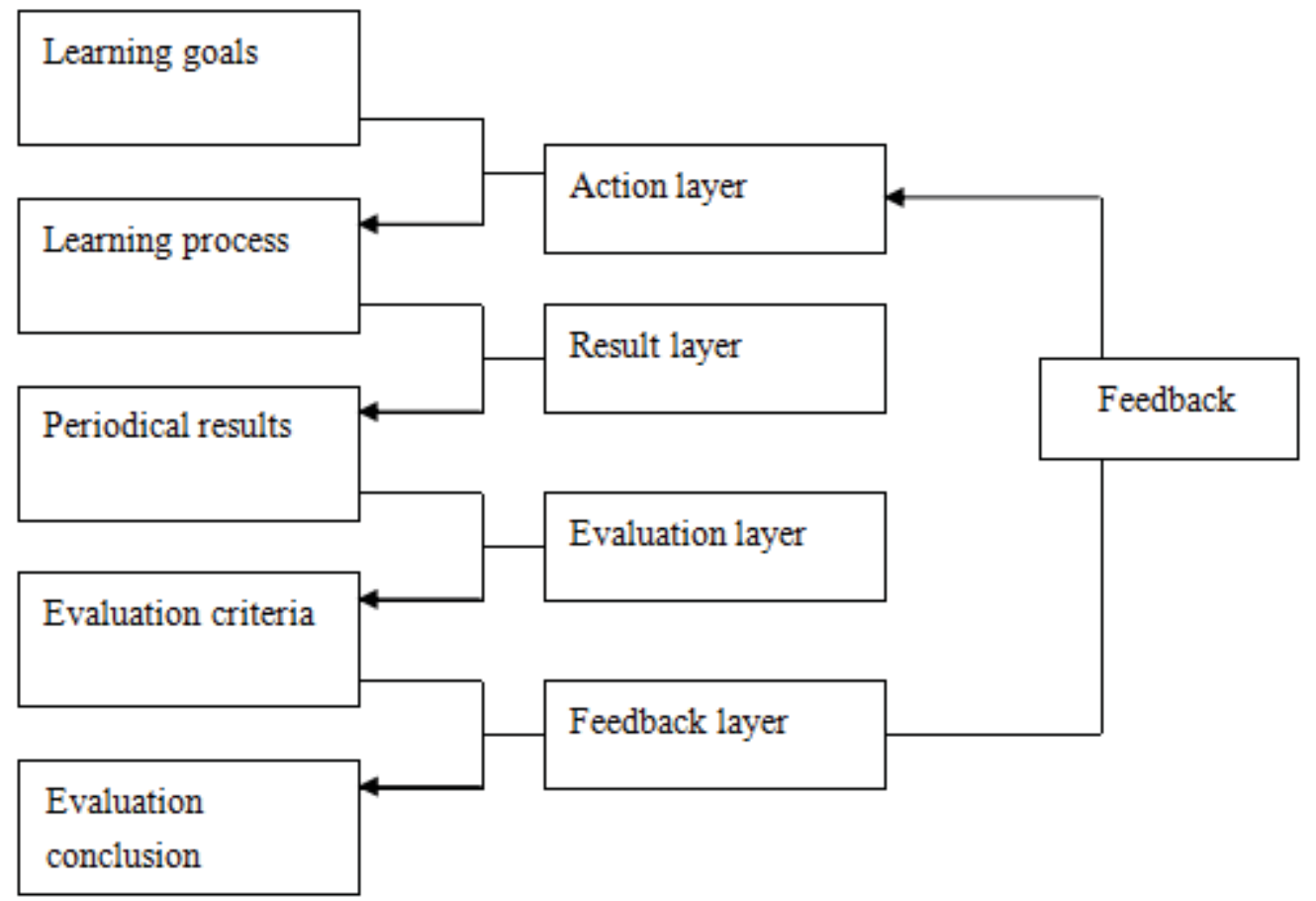

Fig.1 Student self-assessment model 


\section{Factor Analysis in Self - assessment Model}

Learning goals: Students' expectations of school and teachers' requirements for learning will influence the way they learn, and self-evaluation process can be guided by objectives. In the dynamic learning process, these goals should be a decomposition of independent colleges total targets, such as professional training objectives, curriculum objectives, objectives of practice ability and so on. In order to better motivate students, the goal should be oriented and feasible, the school can make students clear their learning goals through different communication methods.

Learning process: It is the implementation of learning plan objectives. The application of self-evaluation will promote students' reflective learning, and also imply the continuous cycle of learning. Students' individual differences and differences in goal needs make them use different learning methods (which may be correct or wrong) to acquire knowledge. When the self-evaluation mechanism plays a role in the academic evaluation system, students in the learning process will constantly adjust different learning methods to form effective learning expectations.

Periodical results: From a most basic perspective, like a way of looking a mirror, you can see yourself what is authentic self through the mirror (Onions, 2011). The assessment of periodical results, provides a more objective facts, can be like a mirror to reflect the students' learning, such as curriculum examination, English competition, community activities reward and so on, can be used for student achievement assessment. Self evaluation give more effective information to improve learning in the stage of achievement, it is the summary and conclusion of learning behavior.

Evaluation criteria: Psychological research shows that people have a kind of self Bias (Self-Enhancing), people tend to be attributed to success, rather than to take responsibility for failure (Self-protection Bias).The mostly mistakes in the self assessment coming from their own prejudices, mainly including too high or too low in the self-assessment. To give full play to the function of self assessment, it is necessary to overcome the possible negative effect of self-evaluation. The key to the realization of the self evaluation mode is to set the evaluation standard and feedback mechanism effectively, because the self evaluation may appear to be distorted or blindly evaluated in the actual operation. According to the principle of constructivism, the study of students is likely to stay in the assimilation stage, but not to the "transformation" effect. Therefore, from the three stages of the learning process to propose different types of evaluation indicators is the very important path to achieve. Indicator decomposition source as shown in Fig. 2 below:

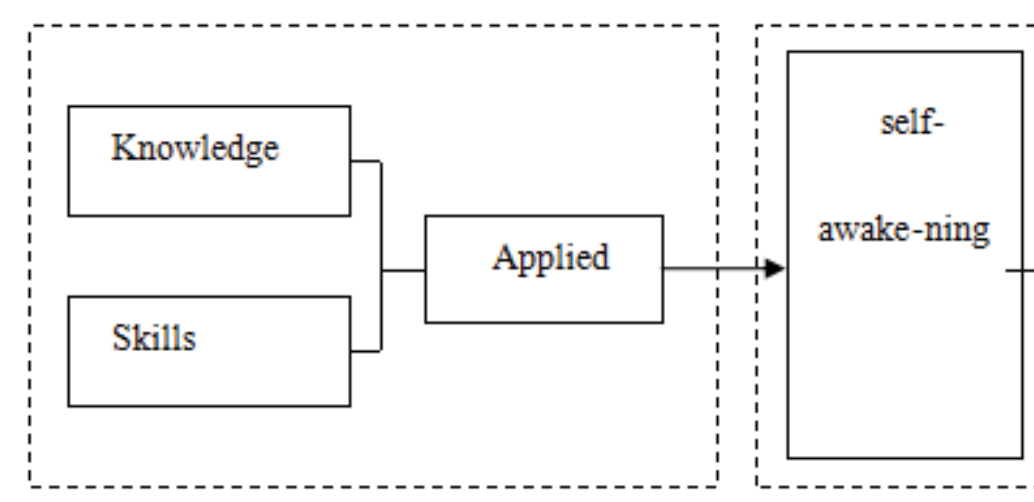

Imitation process<smiles>C[C@@H]1CC[C@H]2CC[C@H]1C2</smiles>

Type I indicator
Conversion process

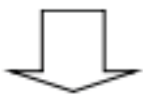

Type II indicator

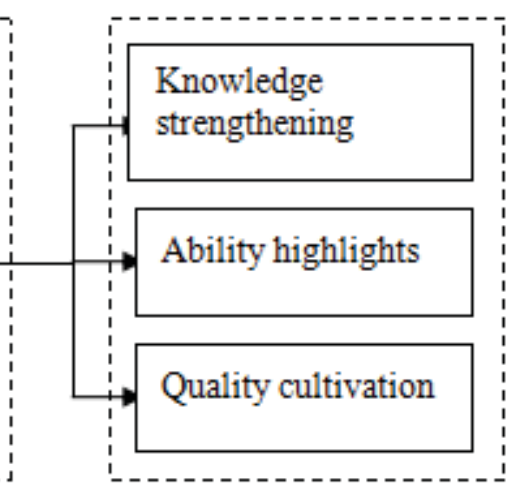

Forming process

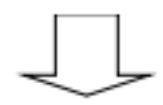

Type III indicator

Fig.2 The source of indicator decomposition 
The source of type I indicator is obtained through the various of system learning, such as classroom indicators, test indicators, operating indicators, the end of the period assessment indicators, teacher evaluation indicators, etc.. This kind of index source is limited, but is relatively clear, which gives the specific index standard, can get good feedback in such indicators. At the same time, it is suggested that a kind of indexes can be measured by standardized indexes, and weight is evaluated according to the importance of knowledge and skills.

Type II indicator is a kind of implicit indicators. The so-called implicit indicators refers to the cognitive indicators in the students' mental activities. These indicators can not be measured by explicit indicators, only through some fuzzy psychological indicators to measure. This kind of indicators is to measure the student's psychological level of conscious thinking, in self-assessment process is also very important, because only oneself can know what he learned.

The third kind of indicators is the inspection indicators, also is the target indicators. Because these indicators provide a more favorable evidence for the Type I and II indicators. For example, the acquisition of the certificate, the award-winning game, the accumulation of practice, the evaluation of external, these can make the indicators richer and more diverse, nor confined to the traditional teaching system. Of course, a problem of the diversity indicators is how to evaluate? Therefore, it is suggested that this kind of evaluation uses the fuzzy evaluation of grade system.

Evaluation feedback: It can affect the maintenance or transformation of students' learning styles. Feedback will also affect the students in the next stage of learning and learning attitude. The teaching mode of independent colleges is usually one-to-many learning mode; that is to say, the single evaluation subject need evaluate the more students. In this process, the collection of information and the realization of feedback is more difficult, resulting in evaluation distortion. In Self-assessment model, students can be grasp this part of the distortion or loss of information, timely formation of feedback with teachers, or self feedback, thereby promoting learning and assessment of effective feedback.

\section{Analysis of Self-assessment effectiveness}

Under the application talents training mode of independent colleges, the innovation of student evaluation is the improvement and innovation of the existing evaluation system according to the characteristics of applied talents. If the traditional evaluation mechanism as a projection of the quality of students, there will be three results in the evaluation level: lack of evaluation, effective evaluation, ineffective evaluation. For example, the practice ability test prone to lack test, and too much emphasis on theoretical knowledge examination may appear invalid evaluation. Traditional evaluation mechanism of projection model as shown in Fig. 3 below:

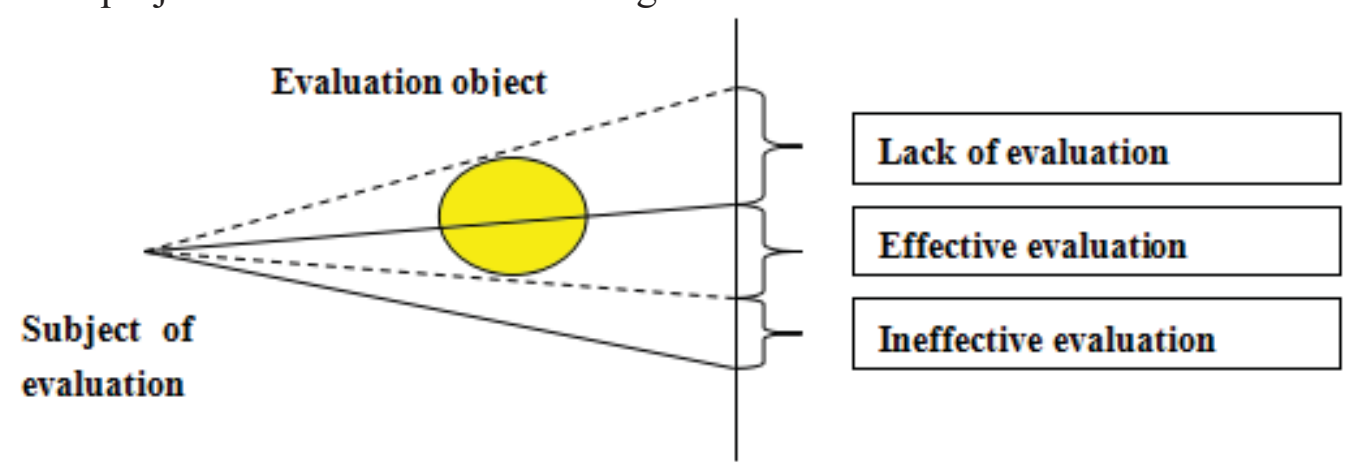

\section{Evaluation level}

Fig.3 Traditional evaluation mechanism of projection model

Self-assessment, not only innovate from the diversification subjects of evaluation, but also the improvement from the way, method and content, thereby helping to reduce the lack of evaluation and invalid evaluation. As a result of their own bias, making self-evaluation can only be used as a complement to the student evaluation system, and can not constitute the main part of the evaluation 
system. The meaning of self-evaluation may play an active role in evaluating feedback and learning. On the other hand, modern information technology is profoundly changing the way of students learning, the more knowledge and more extensive learning channels will guide students to take independent learning. With the "learner centered" philosophy of education are accepted and recognized by many educators, self-assessment effectiveness will be the reform of colleges and universities the practice of accreditation. In view of this, the effectiveness of self-evaluation is not to evaluate without error, but should be the process of personnel training of self-development, self-improvement, and self realization.

\section{References}

[1] Schraw,G. and Dennison, R.S. Assessing metacognitive awareness. Contemporary Educational Psychology. 1994. 19(4), 460-75.

[2] Thomas,P.D\&Bain,J.D.Contextual dependence of learning approaches the effects of assessments. HumanLearning. 1984, 3, 227-240.

[3] S.T.Fiske,S .E.Taylor .Social cognition: Version 2, New York :McGraw Hill, 1991.

[4] Boud D. Enhancing Learning Through Self-assessment[C]// Studies in Continuing Education. 1995.

[5] He Yunfeng, Hu Jian. Function and Role of Self-evaluation [J]. Journal of Social Sciences, Hunan Normal University, 2007, 05:16-20+32.

[6] Lanxin. [J] Learning self-assessment of the Significance of Education. Modern education skill development, 1999 (2): 10-11.

[7] Lin Yinling leaves. On the Surface to Learning and Deep Learning -- A Study Based on the Reform of College Students' academic Evaluation System [J]. Journal of Fujian Normal University (PHILOSOPHY AND SOCIAL SCIENCES EDITION), 2014 (3): 10-11. 